\title{
Application of cold plasma to control the microbiota composition on the surface of potato tubers
}

\author{
Mikhail L. Golovin ${ }^{1}$, Valentina S. Orlova ${ }^{1}$, Svetlana E. Mazina ${ }^{1,2^{*}}$, Valery G. Yakunin ${ }^{3}$, \\ Sergei V. Kuznetsov ${ }^{4}$, Vladimir P. Savinov ${ }^{3}$, Victor Yu. Timoshenko ${ }^{3,4,5}$ \\ ${ }^{1}$ Peoples Friendship University of Russia (RUDN University), Faculty of Ecology, 6 Miklukho- \\ Maklaya Street, Moscow, 117198, Russian Federation \\ ${ }^{2}$ Moscow State University M.V. Lomonosov, Faculty of Chemistry, 119991 Moscow, Russia \\ ${ }^{3}$ Moscow State University M.V. Lomonosov Moscow State University, Faculty of Physics, 119991 \\ Moscow, Russia \\ ${ }^{4}$ Physical Institute named after P.N. Lebedev RAS, 119991 Moscow, Russia \\ ${ }^{5}$ National Research Nuclear University MEPhI, Phys-Bio Institute, 115409 Moscow, Russia
}

\begin{abstract}
A study of the effect of low-temperature plasma on potato tubers was carried out. A comparative assessment of changes in the rate of germination, the size of shoots and the mass of shoots was carried out. Changes in the number of bacteria and fungi on the surface of tubers were analysed for different durations of exposure. It was found that growth characteristics did not change. The number of bacteria on the surface of tubers was significantly reduced due to the exposure to low-temperature plasma.
\end{abstract}

\section{Introduction}

The problem of food shortages is one of the most important today. Traditional methods of cultivation of crops provide less and less yield increases and often lead to environmental pollution.

The development of technologies and the use of unconventional methods of cultivation of crops and the stimulation of increased productivity contribute to an increase in the growth of agricultural production. Low-temperature plasma is one of the promising ways to preserve products, fight pathogens and stimulate the plant organism.

It is widely used to destroy microorganisms on the surface of fruits, including for the destruction of bacterial biofilms $[1,2]$. The proposed methods of product disinfection using cold plasma have a positive effect on shelf life [3, 4].

The object for bioactivation using cold plasma can be biological structures that form a new organism, since the plasma effect on them is close in nature to pulsed concentrated sunlight. An advantage of low-temperature plasma processing is the rapid decay of the ionization products in gas-air mixture that prevents undesired pollution of the irradiated object and environment $[5,6]$. Recently, the low temperature plasma treatment was

* Corresponding author: conophytum@mail.ru 
demonstrated to be efficient for gentle control of the proliferation and growth of infusoria and other microorganisms [7].

The aim of our work was to assess changes in the germination activity of tubers and characteristics of the shoots, as well in in the number of microorganisms on the tubers surface.

\section{Methodology}

Tubers of potato variety Aspia were used for research. The tubers were treated in a cold plasma flow in air at atmospheric pressure. The plasma source was an arc discharge plasmatron with an extended service life and a plasma jet practically free of metallic contaminants [6]. The main structural elements of a plasma source are a water-cooled rod, cathode and a nozzle anode. To protect the cathode from oxidation in the space between the cathode and the anode, an inert gas (Ar) is supplied to the atmosphere, where an arc discharge is initiated.

The structure of the copper anode provides distributed anode arc-discharge binding by supplying the anode process gas (oxygen, air, freons, etc.) to the gas canal. This gas enters a circular slot moving towards the axis of the plasmatron in the radial direction. A vortex zone appears in the zone of mixing with the protective gas of the cathode. This feature leads to a sharp decrease in the current density of the anode and reduces the rate of its erosion.

The tubers were placed at a distance of $24 \mathrm{~cm}$ from the source in a sterile Petri dish. The processing time was 30 seconds, 1, 3, 5, 10 minutes. During the treatment period, the tubers were turned to achieve uniform treatment.

After treatment, potato tubers were placed in individual zip bags, pre-treated with ultraviolet light in a laminar box for 30 minutes. The potatoes were left in closed bags in a thermostatically controlled cabinet without light at a temperature of $24^{\circ} \mathrm{C}$ and a humidity of $60 \%$. Observation of potatoes was carried out every 2-3 days.

Before starting the experiment, prints were made on the surface of the tubers on MPA and Saburo medium. Three impressions were made from each tuber from different sides, the tubers were moved using sterile gloves. At the end of the exposure, prints were also made. One day later, the number of CFU (colony-forming units) of bacteria was determined on the meat-peptone agar (MPA medium). After a day, 2, 3, and 7 days, the number of colonies that appeared on the Saburo medium was determined, and on days 1, 2, and 3, a microscope was used to count the colonies. The result was estimated as the average value of CFU that appeared on the surface of the traces over the entire observation period. The standard deviation was determined.

\section{Results and discussion}

On the 26th day after exposure to low-temperature plasma, shoots were found on the potato tubers. After 60 days, a darkening occurred in the meristematic zone of the shoots, after which the length and mass of the shoots were measured.

It was noted that the tuber, which was exposed to 1 minute, was initially with traces of the fungal disease. It was this tuber that formed the smallest number of shoots that were shorter than shoots of other tubers (Table 1, Fig. 1). 
Table 1. Changes in the germination of potato tubers after exposure to low-temperature plasma.

\begin{tabular}{|l|c|c|c|c|c|c|}
\hline \multirow{2}{*}{$\begin{array}{l}\text { Measured } \\
\text { parameters }\end{array}$} & \multicolumn{6}{|c|}{ Time of exposure to low-temperature plasma } \\
\cline { 2 - 7 } & control & $30 \mathrm{sec}$ & $1 \mathrm{~min}$ & $3 \mathrm{~min}$ & $5 \mathrm{~min}$ & $10 \mathrm{~min}$ \\
\hline $\begin{array}{l}\text { Mass of } \\
\text { tubers, } \mathrm{g}\end{array}$ & $104.78 \pm 0.01$ & $85.94 \pm 0.01$ & $80.24 \pm 0.01$ & $84.14 \pm 0.01$ & $93.08 \pm 0.01$ & $112.19 \pm 0.01$ \\
\hline $\begin{array}{l}\text { Number of } \\
\text { shoots }\end{array}$ & 8 & 8 & 6 & 9 & 10 & 9 \\
\hline $\begin{array}{l}\text { Mass shoots, } \\
\text { g }\end{array}$ & $5.72 \pm 0.01$ & $5.08 \pm 0.01$ & $2.82 \pm 0.01$ & $5.48 \pm 0.01$ & $6.51 \pm 0.01$ & $5.72 \pm 0.01$ \\
\hline $\begin{array}{l}\text { Length shoot } \\
\text { average, mm }\end{array}$ & $31.5 \pm 8.54$ & $23.1 \pm 13.14$ & $13.3 \pm 11.59$ & $22.9 \pm 8.85$ & $24.2 \pm 7.47$ & $18.4 \pm 8.07$ \\
\hline $\begin{array}{l}\text { Mass one } \\
\text { shoot average, } \\
\text { g }\end{array}$ & $0.72 \pm 0.01$ & $0.64 \pm 0.01$ & $0.47 \pm 0.01$ & $0.61 \pm 0.01$ & $0.65 \pm 0.01$ & $0.64 \pm 0.01$ \\
\hline $\begin{array}{l}\text { Ratio mass } \\
\text { shoots/tuber }\end{array}$ & 0.05 & 0.06 & 0.04 & 0.07 & 0.07 & 0.05 \\
\hline
\end{tabular}

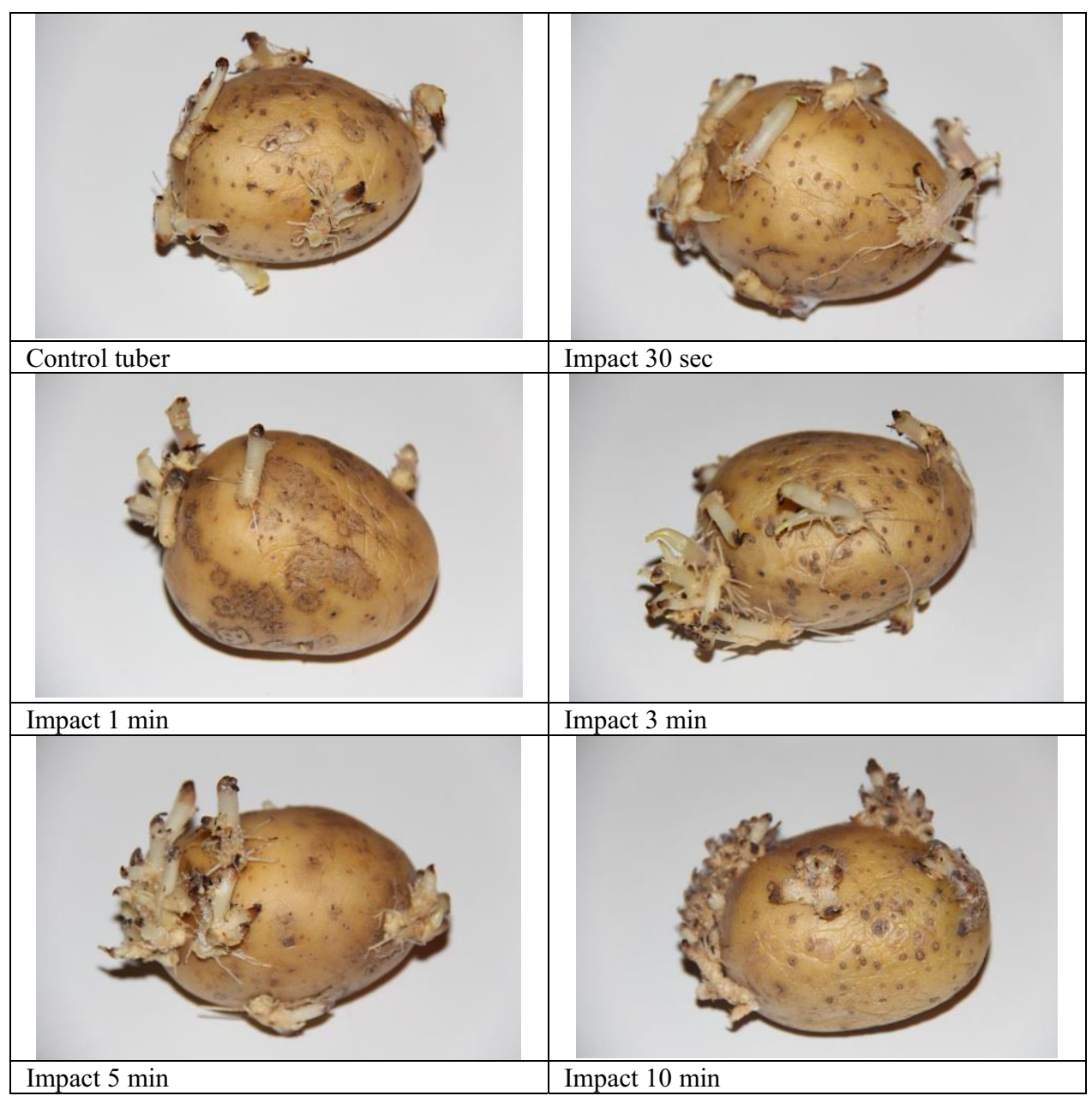

Fig. 1. Appearance of germinated tubers 60 days after exposure to the low-temperature plasma. 
No significant differences in the mass of shoots were found in different experiments. Germination occurred at the same time, regardless of the duration of exposure to cold plasma. The treatment of tubers with low-temperature plasma had the greatest effect on the number of colony-forming units of bacteria on the surface of tubers. Even a short exposure to cold plasma led to a decrease in the number of bacteria. A change in the number of fungi was noted after 5 minutes of exposure (Table 2).

Table 2. Changes in the number of microorganisms on the surface of tubers after exposure to lowtemperature plasma.

\begin{tabular}{|l|c|c|c|c|c|c|}
\hline \multirow{2}{*}{ Measured parameters } & \multicolumn{5}{|c|}{ Time of exposure to low-temperature plasma } \\
\cline { 2 - 7 } & $\begin{array}{c}\text { CFU before } \\
\text { cold plasma } \\
\text { treatment }\end{array}$ & $30 \mathrm{sec}$ & $1 \mathrm{~min}$ & $3 \mathrm{~min}$ & $5 \mathrm{~min}$ & $10 \mathrm{~min}$ \\
\hline $\begin{array}{l}\text { Colony forming units of } \\
\text { bacteria } / \mathrm{cm}^{2}\end{array}$ & $297 \pm 16$ & $29 \pm 3$ & $27 \pm 3$ & $23 \pm 6$ & $18 \pm 3$ & $4 \pm 2$ \\
\hline Fungi $/ \mathrm{cm}^{2}$ & $6.3 \pm 1.5$ & $6.3 \pm 1.5$ & $6.3 \pm 1.5$ & $5.7 \pm 1.5$ & $3.3 \pm 1.5$ & $0.3 \pm 0.6$ \\
\hline
\end{tabular}

The development of micromycetes was found on the shoots and tuber, which was treated for 10 minutes. Perhaps this is due to a decrease in the number of bacteria on the surface of the tuber and a decrease in competition with micromycetes. Another reason may be the increased survival of micromycete spores in comparison with bacteria during treatment with cold plasma.

As a result of the experiment, there were no significant changes in tuber germination and characteristics of shoots after exposure to low-temperature plasma. In the literature, it is noted that pre-sowing treatment with cold plasma of seeds can have a positive effect on their germination [8], primary experiments with potato tubers did not reveal a stimulating effect on the formation of shoots.

The exposure of bacteria to low-temperature plasma is usually accompanied by their destruction. The mechanism of action depends on the composition of the gas environment, temperature, humidity, voltage and frequency is discussed in detail in the literature [9]. This study also found an effect on micromycetes. This opens up prospects for studying the resistance to the action of low-temperature plasma of mycelium and fungal spores.

\section{Conclusion}

The obtained data show that the low-temperature plasma irradiation for 0.5-10 minutes does not cause significant changes in the germination of tubers and the formation of shoots. The plasma action for 5-10 minutes causes a decrease in the number of mushroom propagules on the surface of the tubers. Bacteria are most sensitive to the action of low-temperature plasma. Even after 0.5 min exposure, the number of bacteria on the surface of the tubers significantly drop down. The obtained results indicate that the low temperature plasma can control selectively the biota composition on potato tubers that is promising for potential applications in agrotechnology and food industry.

\section{References}

1. C. Nguyenthe, F. Carlin, Crit. Rev. Food Sci. Nutrition, 34, 371-401, (1994).

2. M. Vleugels, G. Shama, X. T. Deng, E. Greenacre, T. Brocklehurst, M. G. Kong, IEEE Transactions on plasma science, 33(2), 824-828 (2005) 
3. H. Wang, H. Feng, W. Liang, Y. Luo and V. Malyarchuk, J. Food Science 74 (1), E8E15 (2009)

4. K. D. Weltmann, R. Brandenburg, T. von Woedtke, J. Ehlbeck, R. Foest, M. Stieber and E. Kindel, J. Phys. D: Appl. Phys. 41, 194008 (2008).

5. E. B. Menshchikova, V. Z. Lankin, N. K. Zenkov, I. A. Bondar, N. F. Krugovykh, V. A. Trufakin, Oxidative stress. Pro-oxidants and antioxidants ("MIR", Moscow, 2006) (in Russian).

6. V. Riaby, V. Savinov, V. Yakunin, Yu. Pirogov, I. Rodin. Biomed. Eng 51(3), 195 (2017).

7. V. P. Savinov, V. G. Yakunin, O V Karpukhina, A. N. Inozemtsev, V. Yu. Timoshenko, V. A. Riaby, J. Phys.: Conf. Ser. 1348, 012007 (2019)

8. Yu. A. Gordeev, N. Ya. Shmyreva, Fertility. 5, 26-27, (2009) (in Russian).

9. P. Bourke, D. Ziuzina, L. Han, P.J. Cullen, B.F. Gilmore, J. App. Microbiol., 123, 308324, (2017) 